\title{
3D MODEL FOR INDOOR SPACES USING DEPTH SENSOR
}

\author{
Mukhtar, N.F ${ }^{1}$, Azri, S. ${ }^{1}$, Ujang, U. ${ }^{1}$, Cuétara,M.G. ${ }^{2}$, Retortillo,G.M. ${ }^{2}$ and Mohd Salleh, S. ${ }^{1}$ \\ ${ }^{1}$ Dep. of Geoinformation, Faculty of Built Environment and Surveying, Universiti Teknology Malaysia (UTM), Johor, Malaysia \\ noorulya2@live.utm.my, suhaibah@utm.my, mduznir@utm.my \\ ${ }^{2}$ Planta 5 a Oficina 16, Calle Luis Álvarez Lencero, 3, 06011 Badajoz, Spain \\ ceo@ecapture3d.com, guillermo@ecapture3d.com
}

KEY WORDS: Indoor spaces, 3D model, 3D visualization, point clouds, depth sensor.

\begin{abstract}
:
In recent years, 3D model for indoor spaces have become highly demanded in the development of technology. Many approaches to $3 \mathrm{D}$ visualisation and modelling especially for indoor environment was developed such as laser scanner, photogrammetry, computer vision, image and many more. However, most of the technique relies on the experience of the operator to get the best result. Besides that, the equipment is quite expensive and time-consuming in terms of processing. This paper focuses on the data acquisition and visualisation of a 3D model for an indoor space by using a depth sensor. In this study, EyesMap3D Pro by Ecapture is used to collect 3D data of the indoor spaces. The EyesMap3D Pro depth sensor is able to generate 3D point clouds in high speed and high mobility due to the portability and light weight of the device. However, more attention must be paid on data acquisition, data processing, visualizing, and evaluation of the depth sensor data. Hence, this paper will discuss the data processing from extracting features from $3 \mathrm{D}$ point clouds to $3 \mathrm{D}$ indoor models. Afterwards, the evaluation on the $3 \mathrm{D}$ models is made to ensure the suitability in indoor model and indoor mapping application. In this study, the 3D model was exported to 3D GIS-ready format for displaying and storing more information of the indoor spaces.
\end{abstract}

\section{INTRODUCTION}

3D models of indoor environments are important in many applications, but they usually exist only for newly constructed buildings. In recent years, 3D model for indoor spaces became highly demanded in the development of technology (Azri et. al. 2019; Keling et. al. 2017; Ujang et. al. 2018; Azri et. al. 2016). Many approaches to 3D visualisation and modelling especially for indoor environment, was developed such as laser scanner, photogrammetry, computer vision, image and many more. Construction of 3D indoor model is more difficult than the outdoor scene. This is due to the limited space of the indoor environment as well as the complexity of object features in the indoor scene. Automated approaches using imagery and/or point clouds to model indoor environments can make the process easier, faster and cheaper (Díaz Vilariño, 2015). Visualisation of spatial 3D object allows the user to easily access complex object features in a particular application.

Due to the fast paced growth of technology, there are high demands for $3 \mathrm{D}$ models of indoor environments to support better analysis and decision making (Azri et. al. 2014). Therefore, several techniques and approaches have been developed to acquire 3D data for indoor spaces such as mapbased approach, image-based approach, point cloud-based approach and integrated approach (Xiao et al., 2007). As a result of the development of technology for 3D phenomena, expansive use and need of 3D GIS applications have emerged. 3D GIS is a system which is able to represent, manage, and manipulate, analysis information links with $3 \mathrm{D}$ environment (Rahman, 2000). 3D models in GIS environment can provide a better understanding and analysis to facilitate better decision making (Mohd et. al. 2017; Izham et. al. 2011).

This paper is focused on the data acquisition and visualization of a 3D model for an indoor environment using a depth sensor. For 3D modelling indoors, the use of the depth sensor is recommended (capture/depth sensor). This sensor is a projector of infrared points combined with a CMOS sensor which allows the capturing of the environment in $3 \mathrm{D}$ in any light conditions (Mérida, 2016). The useful detection range of the depth sensor is up to 4 meters (mainly indoors).

Currently, one of the popular approaches for generating 3D indoor maps is constructed by using point clouds (Hong et al., 2015). It is a fast technique to generate an indoor scene map. A terrestrial laser scanner is often used as the main mapping technology for the indoor 3D model by providing fast and accurate 3D data. However, the field process to acquire the indoor 3D data using a terrestrial laser scanner heavily relies on the expert's field experiences (Kim et al., 2015). 3D indoor mapping with points cloud and additional data such as RGB color can be used in various applications such as indoor scene visualization, generation of automated floorplan, gaming, reverse engineering, navigation, simulation and others (Chen et al., 2016).

In this study, EyesMap3D Pro by Ecapture was used to collect 3D data of the indoor spaces in 3D GIS Research Lab - C05 building of Faculty of Built Environment and Surveying. The EyesMap3D Pro depth sensor is able to generate 3D point clouds at high speed and high mobility due to the portability and light weight of the device. However, more attention must be paid to the data acquisition, data processing, visualising, and evaluation of the 3D indoor model by depth sensor. Hence, this paper will discuss the data processing from extracting features of indoor spaces from 3D point clouds to 3D indoor models. Afterwards, the analysis and evaluation of the 3D models are carried out to ensure the suitability in indoor model and indoor mapping application. In this study, the 3D model was exported to 3D GIS-ready format for displaying and storing additional information of the indoor spaces. This paper shows that 3D model by depth sensor is applicable for indoor spaces applications. 


\section{RESEARCH BACKGROUND}

\subsection{D Indoor Mapping Approaches}

Many approaches to generating 3D indoor mapping have recently been proposed using different techniques. Construction of 3D indoor maps is more difficult than outdoor scene. This is due to limited space in the indoor environment and inability of the signal to reach the instrument in the building (Chen et al., 2014).

Currently, one of the popular approaches of generating 3D indoor map is constructed by using point clouds (Hong et al., 2015). It is a faster technique to generate an indoor scene map. A terrestrial laser scanner emerges as a main mapping technology for the indoor $3 \mathrm{D}$ model by providing fast and accurate 3D data. However, the field process to acquire the indoor 3D data using a terrestrial laser scanner heavily relies on the expert's field experiences (Kim et al., 2015). 3D indoor mapping with points cloud and additional data such as RGB color can be used in various applications such as indoor scene visualisation, generation of automated floorplan, gaming, reverse engineering, navigation, simulation and etc. (Chen et al., 2016).

Another approach for generating the 3D map of an indoor environment is by using a low cost $3 \mathrm{D}$ sensor (Kinect version 2.0). It requires the combination of global point cloud of indoor scene with a terrestrial laser scanner (TLS) (Lachat et al., 2016).

\subsection{Fundamentals of Depth Sensor and Laser Scanning}

There are several traditional sensors such as terrestrial laser scanner (TLS) used for 3D data acquisition. A distance from sensor to object can be measured by laser light from laser scanner (Böhler et al., 2002). The distance measurement which is the ranging depends on the laser light. The 3D models data from the terrestrial laser scanner (TLS) is more accurate and suitable for high resolution job. However, it becomes difficult when it comes to objects that have a very complex shape and have to scan more than once to get the complete object (Bornaz, 2004).

The kinetic depth sensor has become an option, apart from the traditionally used sensor like a laser scanner, for producing 3D information for 3D applications. Kinect sensor was developed by Microsoft Corp. using depth sensor technology. The emission of an infrared (IR) pattern and the simultaneous image capture of the IR image with a (traditional) CMOS camera that is fitted with an IR-pass filter is a basic principle of Kinect depth sensor (Andersen et al., 2012).

\subsection{EyesMap3D Pro Fundamentals}

The Eyes 3D Pro is a depth sensing technology developed by the eCapture3D company. eyesMap3D PRO is a High Capacity Device that allows measurement, 3D modelling and documentation of the environment around us. This measurement device, with its integrated and calibrated a HR cameras, is based on photogrammetry, and in addition relies on other sensors to capture detailed 3D models of the environment and complex 3D geometric objects quickly and conveniently. For 3D modelling indoors, the use of the depth sensor is recommended (capture/depth sensor).
The device has 3 main parts which is infrared camera, a RGB camera and infrared projector. Each part has a function to get the point cloud data. Infrared projector shoots the dots in an irregular pattern that projected in the target which is the indoor environment. An irregular pattern of dots is formed due to infrared light that diffracted during the infrared generated at the projector. Infrared camera which is the CMOS sensor that can detect and record the infrared light reflected from the features. By combining an IR camera with an irregular pattern of dots, the amount of depth is computed based on each pixel on the scene. The specifications for the depth sensor of Eyes 3D Pro are as follows:

\begin{tabular}{|l|l|}
\hline Aspect & Description \\
\hline Resolution & 13 Megapixels \\
Focus & Manual/automatic \\
Exposure Time & Manual/automatic \\
Field of view $(\mathrm{H}, \mathrm{V})$ & $58^{\circ} 42^{\circ}$ \\
Range & $4 \mathrm{~m}$ \\
Color & RGB \\
Comm. Port & USB 3.0 \\
Accuracy & $4 \mathrm{~mm}-1.5 \mathrm{~m}$ \\
Export Format &. $\mathrm{ply} \mathrm{.obj}$ \\
Weight & $850 \mathrm{~g}$ \\
Dimension & $23.5 \times 5 \times 8.5 \mathrm{~cm}$ \\
\hline
\end{tabular}

Table 1 EyesMap3D Pro specifications

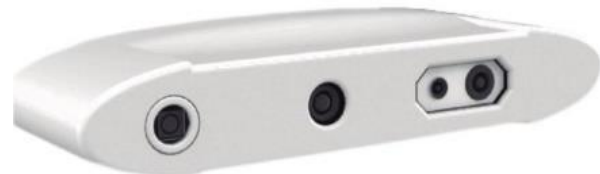

Figure 1 EyesMap3D Pro depth sensor

\section{METHODOLOGY}

Proper planning is needed to achieve the objective and produce a good quality of output. In this study, the methodology is divided into five phases which is preliminary study, data acquisition, data processing, data modelling, and ended with result and evaluation of the $3 \mathrm{D}$ data model. The workflow of the study is illustrated in figure 1 . All the phases in the methodology were planned, organised, and implemented to accomplish the purpose of this study and every phase is interrelated.

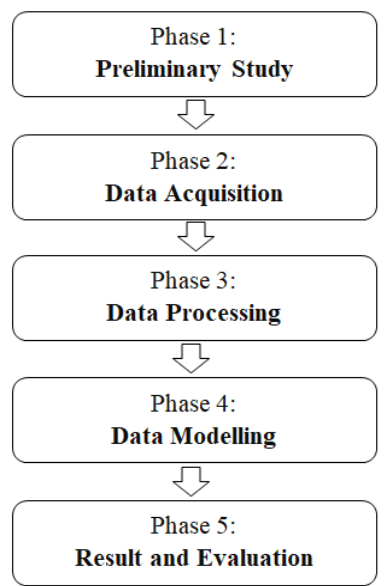

Figure 2 Workflow of the research methodology 
The International Archives of the Photogrammetry, Remote Sensing and Spatial Information Sciences, Volume XLII-4/W16, 2019 6th International Conference on Geomatics and Geospatial Technology (GGT 2019), 1-3 October 2019, Kuala Lumpur, Malaysia

\subsection{Preliminary Study}

In the preliminary study, literature review is done to obtain the knowledge and ideas for choosing suitable software and methods to accomplish this study. This phase also included the study of operation of depth sensor, survey the study area and study of software for processing and modelling 3D model for indoor spaces. In a nutshell, the role of this phase is to give the researchers a clear view on how to carry out the activities of the work.

\subsubsection{Tools}

In this study, the scanning process is done by using two type of scanners. To achieve the objective of the study, new depth sensor technology was used which is the Eyes 3D Pro (Figure 2) developed by eCapture 3D company. Another scanner used in this study is laser scanning which is Terrestrial Laser Scanning (Figure 3) to make a simple comparison with EyesMap 3D pro device.

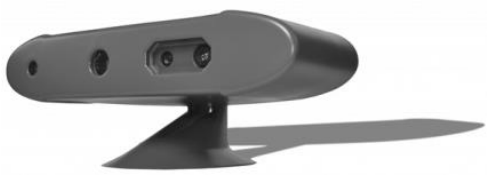

Figure 3 EyesMap 3D Pro Scanner

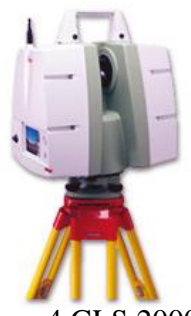

Figure 4 GLS 2000

\subsubsection{Area of study}

The area of study has to be analysed first in order to carefully plan and find the efficient solution to any problem that may occurred before or after field survey. For the area of study, Postgraduate Meeting Room was chosen which is located at 3D GIS Research Lab - C05 building of Faculty of Built Environment and Surveying. Figure 5 shows the study area of 3D GIS Lab II.

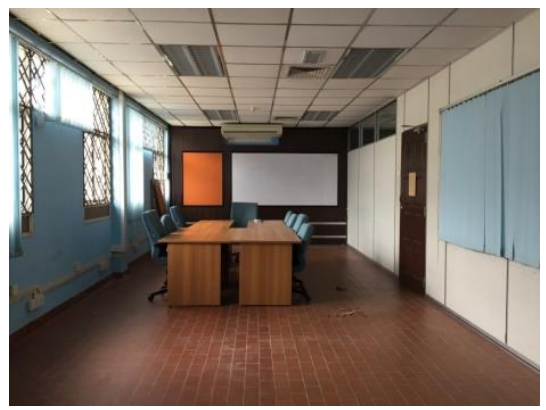

Figure 5 3D lab GIS

\subsection{Acquisition and Processing}

In this study, EyesMap3D pro device (depth sensor) was used to collect 3D point cloud of indoor spaces. EyesMap3D PRO is a High Capacity Device that allows measurement, 3D modelling and documentation of the environment around us. This measurement device, with its integrated and calibrated a HR camera, is based on photogrammetry, and in addition relies on other sensors to capture detailed 3D models of the environment and complex 3D geometric objects quickly and conveniently.

\subsubsection{Calibration}

During the data acquisition process, calibration is carried out to ensure the accuracy of the data to be evaluated at the end of the study. The 3D calibration frame was used to make calibration to the depth sensor. Each pole on the frame was attached with points target from 1 until 146.

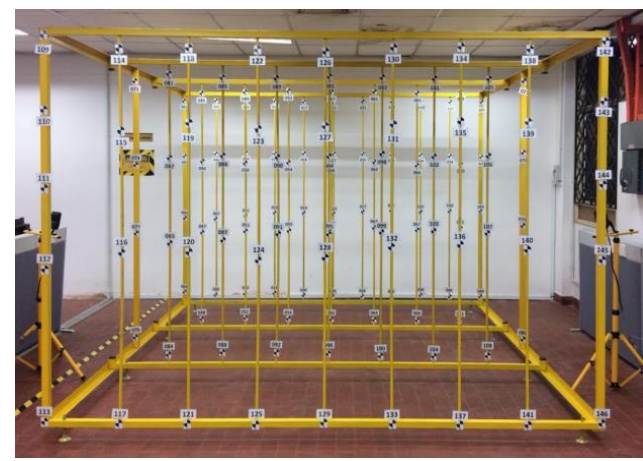

Figure $63 \mathrm{D}$ calibration frame

The actual distance of the target is obtained based on conventional technique, which is by using Topcon total station. All the data was recorded and computed by using 3D calibration frame (computations tools) software.

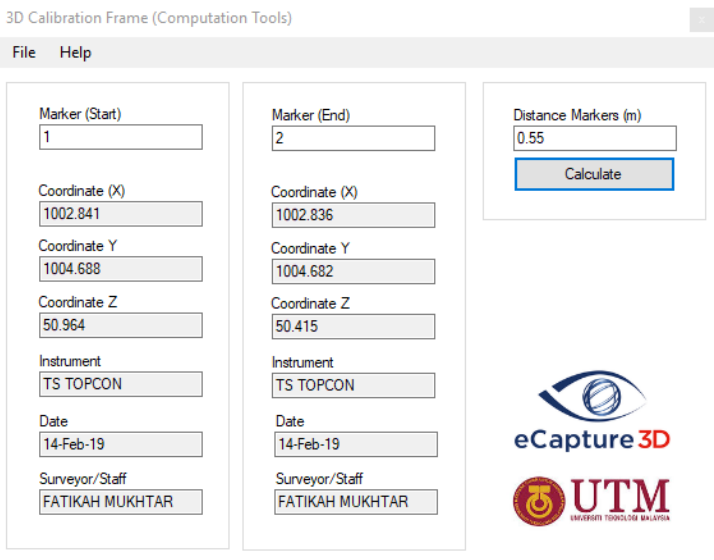

Figure 7 3D calibration Frame (computations tools) software

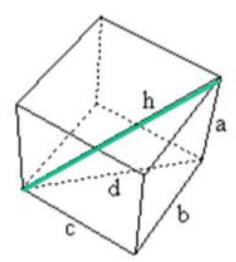

$h=\sqrt{ } a^{2}+b^{2}+c^{2}$

Equation 1 Pythagoras Theorem

Basically, this software used Pythagoras theorem formula to calculate the distance based on coordinate data as illustrated in Figure 8 . For depth sensor, a 3D model was generated by scanning the calibration frame to calculate the distance based on point cloud produced. 3D models generated with EyesMap3D pro device are already scaled. 


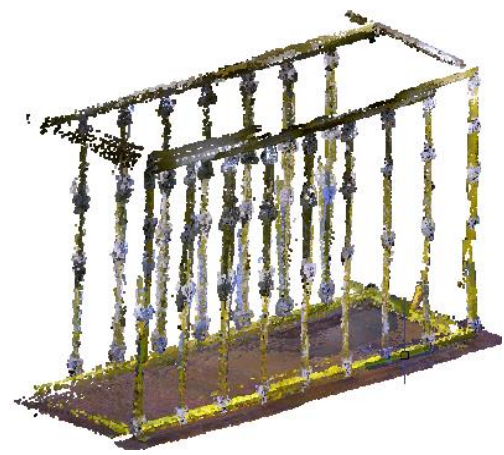

Figure 8 3D model of calibration frame

Next, the distance recorded by total station and depth sensor is compared. The difference between the points recorded (x,y,z distance) by both devices is small. It can be considered that the depth sensor has a high accuracy if the acquisition of 3D point cloud data technique is done correctly.

\begin{tabular}{|l|l|c|c|c|c|}
\hline From & To & Direction & $\begin{array}{l}\text { Distance } \\
\text { from } \\
\text { TLS(m) }\end{array}$ & $\begin{array}{l}\text { Distance } \\
\text { from Depth } \\
\text { Sensor(m) }\end{array}$ & $\begin{array}{l}\text { Different } \\
(\mathrm{m})\end{array}$ \\
\hline 146 & 144 & $\mathrm{x}$ & 0.40 & 0.38 & 0.02 \\
\hline 144 & 143 & $\mathrm{y}$ & 0.44 & 0.41 & 0.03 \\
\hline 140 & 107 & $\mathrm{z}$ & 1.00 & 0.99 & 0.01 \\
\hline
\end{tabular}

Table 2 Comparison two data distance from calibration frame

\subsubsection{Data acquisition and processing}

In this study, the indoor 3D model is generated using EyesMap3D Pro device that have the ability to collect point cloud data. This sensor projects infrared points combined with a CMOS sensor allowing the capture of the environment in 3D in any light conditions. The useful detection range of the depth sensor is up to 4 meters (mainly indoors).

EyesMap3D software is specially designed for EyesMap3D pro device and it was used in this study to process the 3D point cloud by the depth. One of the steps required for acquisition of 3D point cloud by EyesMap3D pro device is to warm up the sensor before start the capture. This reduces noise and able to increase the accuracy. The optimal time to warm up the sensor is 13 minutes.

After the sensor is ready, a database is created in the software to store the data of the project. The object in indoor spaces was scanned after the database was created. Among the aspects that need to be considered during the object scanning is the distance of object scanned need be close with the device at least 1 or $1.5 \mathrm{~m}$ (recommended). The place to scan also requires good texture. Targets or other elements should be used and white walls or other homogeneous areas should be avoided. To make sure the coverage of point cloud encompasses the whole scene, the same place should be scanned at least two times looking for loop closure (green color in the windows of loop closure matching points).

During the object scanning process, the centre panel (camera preview and 3D generation in real time) is displayed on screen. This panel is divided into four parts. The left side shows the video preview with the matching points founds in different frames. Also indicated in this window is the quality of the data detected, differentiated by different colors whereby; Green is good, yellow is acceptable, red is rejected. The system also uses this color scale, to indicate the loop closure adjustment quality in real time.

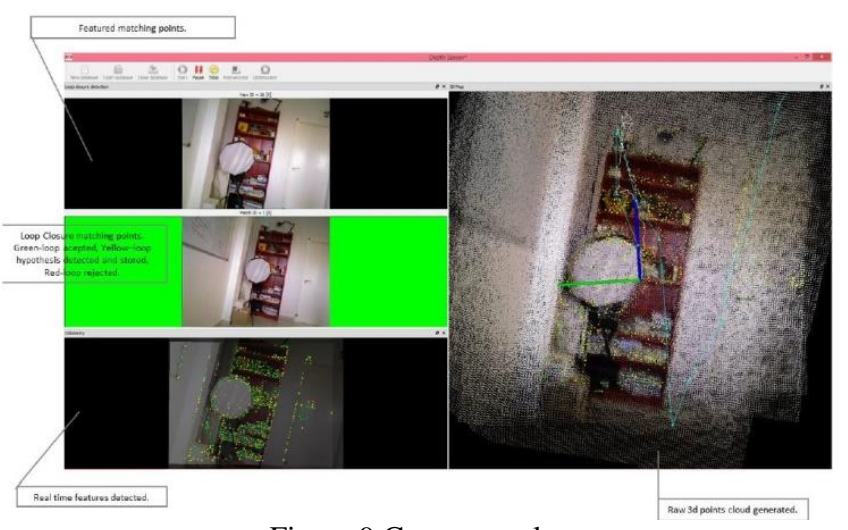

Figure 9 Centre panel

The data collected from a depth sensor represented 3D coordinates $(\mathrm{x}, \mathrm{y}$, and $\mathrm{z})$. The system also executed postprocessing of the data after scanning to adjust geometrically the 3D model. Optimisation process is also done by the system to improve the model and store the data into the viewer. The resulting $3 \mathrm{D}$ point cloud generated by depth sensor displayed in $3 \mathrm{D}$ viewer.

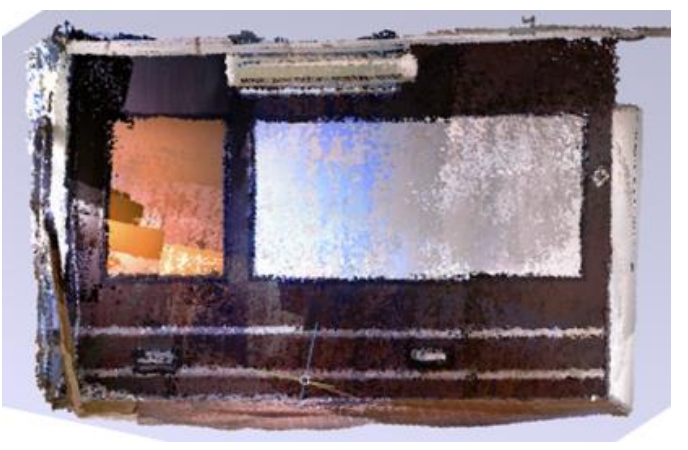

Figure $103 \mathrm{D}$ point cloud by depth sensor

In this study, terrestrial laser scanning (TLS) was also used to generate point cloud. Point cloud that generated by GLS 2000 was used to compared the density of point cloud data with the data from depth sensor for evaluation phase at the end of the study.

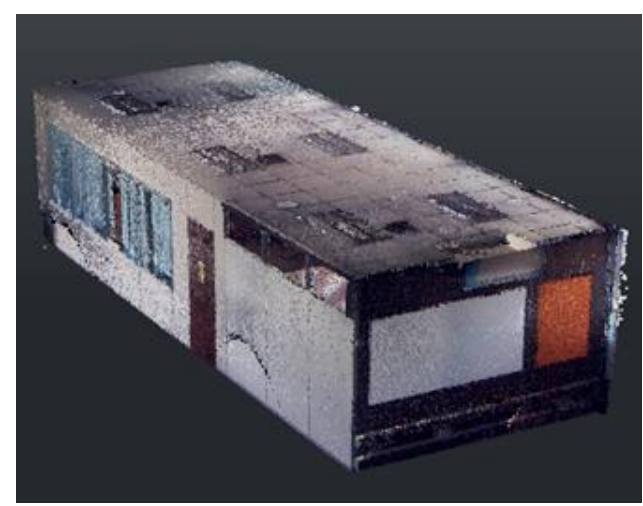

Figure $113 \mathrm{D}$ point clouds by terrestrial laser scanner 


\subsection{D Data Modelling}

This operation is to form a surface model of objects or features based on point clouds. Basically, 3D objects consist of geometric and textural models. Lines, surfaces, volumes are the basic elements of geometry used to construct a 3D model. In this study, geometry was used for modelling such as wall, windows, boards, door and air conditioner models.

\subsubsection{Data Conversion}

In this study, the modelling process was done by using AutoCAD2016. The 3D point clouds generated in EyesMap3D software is in .ply format. The data converted to .rcp in Revit software and imported to AutoCAD 2016 for reconstruction of 3D model. AutoCAD2016 was used in this study because this software is able to import point cloud and it is an easy-to-use 3D modelling software. AutoCAD2016 able to model the object point cloud from two-dimensional wireframe to three-dimensional (conceptual, shaded, x-ray, realistic, et.).

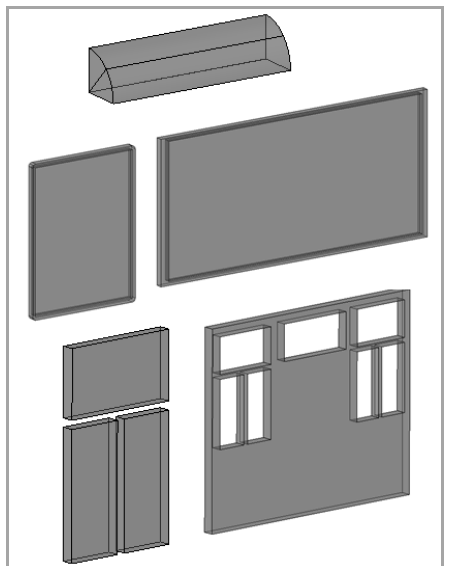

Figure 12 Indoor assets constructed as geometry model using AutoCAD 2016.

Texture and color is an important part of the 3D model to produce a more realistic model with the real world.

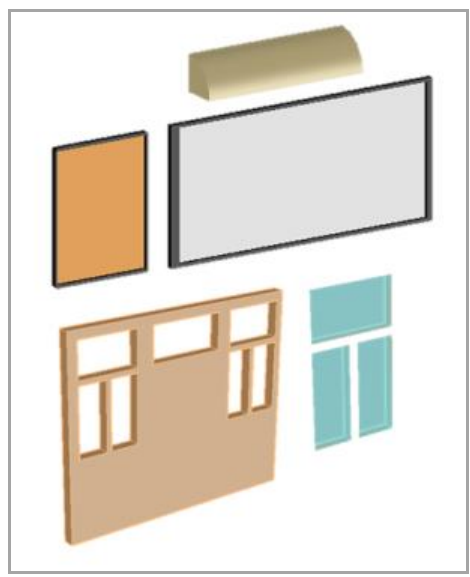

Figure 13 Indoor assets applied texture and color

\subsubsection{Point Cloud Noise Removal}

The raw point cloud data produced by depth sensor often has noise as an effect of physical error, limitations of the sensor, and illuminations or artefact in the scene. Therefore, noise filtering is performed to reduce the amount of points and remove unnecessary points before further processing. Removal of the noise was done in AutoCAD 2016 by cropping the unnecessary point cloud data.

\subsubsection{Digitizing and modeling 3D data.}

This study obtained point cloud data from part to part of the indoor spaces because of the limitation of movement in the study area. The data was merged in AutoCAD 2016 and the point cloud digitized to 3D indoor model. All the objects of indoor spaces were stored as different layers such as wall, windows, door, board, air conditioner, pipe cover and etc.

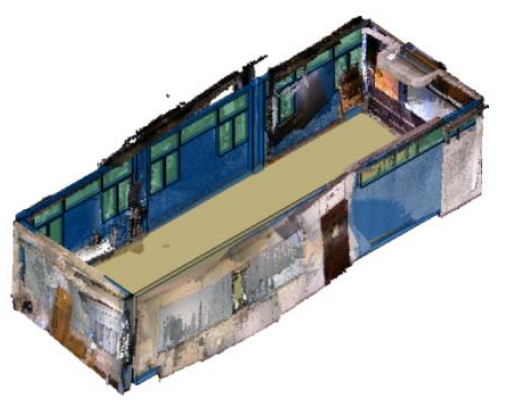

Figure 14 Digitizing 3D model based on point clouds data

\subsubsection{D model to GIS-ready format}

3D model in GIS environment can provide more understanding and analysis in decision making. 3D GIS data not only provides $3 \mathrm{D}$ visualisation, information and analysis, but it is also capable to work with attributes linked to GIS database. In this study, ArcScene was used to display and store information of the 3D indoor model as GIS-ready format. In ArcScene, all 3D models must be stored in a geodatabase as stand-alone feature classes.

The Import 3D Files tool in ArcToolbox is used to import the COLLADA file (*.dae) and create geodatabase of 3D models in ArcScene. To export the 3D model in ArcScene, the 3D model are converted to .dae format in SketchUp first and then exported to ArcScene.

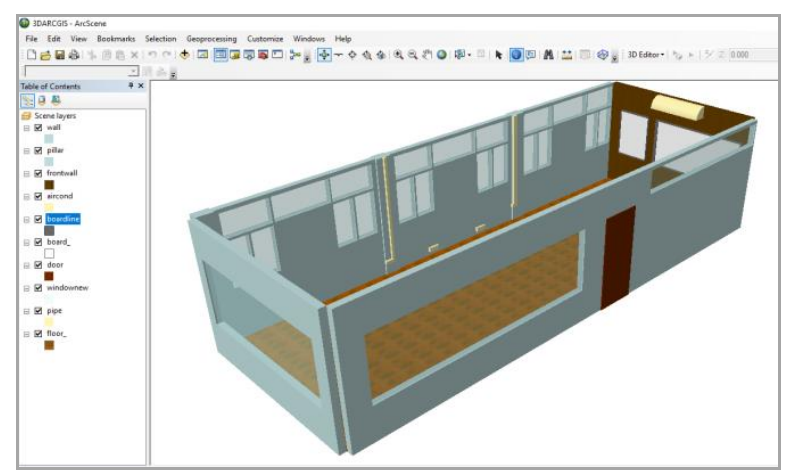

Figure 15 3D model in GIS environment

\section{EVALUATION AND RESULT}

In this study, a set of point cloud data of the 3D GIS Lab for indoor spaces was collected using the EyesMap3D pro device. The complete model indoor space model was successfully constructed using AutoCAD 2016. 


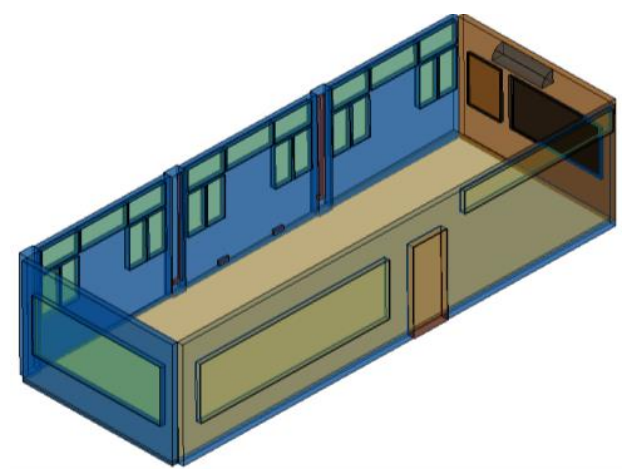

Figure 16 3D model of indoor spaces digitized in AutoCAD 2016

The data was also successfully exported to GIS-ready format by using ArcScene for data storing and displaying in GIS environment.

\subsection{Indoor model requirement}

After the process of modelling the 3D model data is done, an evaluation of the 3D indoor model generated by a depth sensor with the existing specification for indoor application was carried out. The 3D indoor model generated by the depth sensor was compared with several specification/requirement of indoor model to ensure the suitability in application.

In indoor model for navigation requirement, an indoor environment shall capture the general semantic information for a specific building and be represented by all spaces belonging to this indoor environment (G. Brown, 2012). The data obtained in this study does not fulfill the requirements for the representation of indoor obstacles/non-navigable spaces. Basically, the indoor objects represented in this study only captured the visible surfaces of a room.

Density of point cloud is also vital in the construction of 3D model to make sure the 3D model represents the exact shape and size of the object scanned. The point cloud was obtained from high accuracy equipment which is terrestrial laser scanner (Y.Lee et. al, 2013). It was therefore assumed that the laser scanner point cloud is sufficiently accurate and dense to serve as reference for the accuracy evaluation of the depth sensor point cloud.
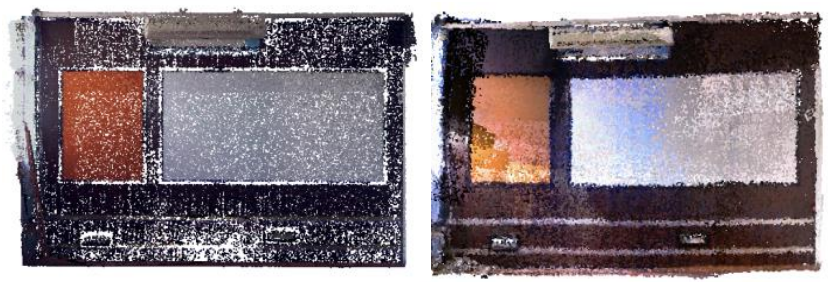

Figure 17 Comparison of point cloud between TLS (left) and depth sensor (right)

Apart from that, accuracy measures the closeness of the reconstructed elements in the source model to their corresponding elements in the reference model. The measurements between depth sensor point clouds data compared with the point clouds data obtained by laser scanner and the exact measurement by using measure tape. The accuracy defined based on the distance between horizontal (x), vertical $(y)$, and depth $(\mathrm{z})$ in the source and reference models.
The table below shows the comparison of distance between point cloud obtained by depth sensor and laser scanner and real measurement by measure tape (as reference). In order to get a systematic accuracy assessment, the evaluation of the estimate accuracy was carried out using the equation:

$$
\text { RMSE }=\sqrt{\frac{\sum_{[1}^{N}(x-\bar{x})^{a}}{n}}
$$

Equation 2 Root Mean Square Error formula

The root-mean-square error (RMSE) was used to measure the differences between values predicted by a model or and the values actually observed. It is acceptable to measure the error and estimate the quality of features by using RMSE to describe accuracy of features. The lower the RMSE value, the better the accuracy (Mao and Shi (2008).

Therefore, the evaluation in this study included the comparison of measurement between conventional method (measure tape) and point cloud data, TLS and depth sensor.

\begin{tabular}{|c|c|c|c|c|c|}
\hline $\begin{array}{c}\text { Featur } \\
\mathbf{e}\end{array}$ & $\begin{array}{c}\text { Dimen } \\
\text {-sions }\end{array}$ & $\begin{array}{c}\text { Measure } \\
\text { Tape } \\
(\mathbf{m})\end{array}$ & $\begin{array}{c}\text { TLS } \\
(\mathbf{m})\end{array}$ & $\begin{array}{c}\text { Diff. } \\
(\mathbf{X})\end{array}$ & $\mathbf{X}^{\mathbf{2}}$ \\
\hline $\begin{array}{c}\text { Electric } \\
\text { box (L } \\
\text { shape) }\end{array}$ & Height & 0.100 & 0.096 & 0.004 & 0.000016 \\
\cline { 2 - 6 } & Width & 0.150 & 0.143 & 0.007 & 0.000049 \\
\cline { 2 - 6 } & Length & 0.178 & 0.171 & 0.007 & 0.000049 \\
\hline $\begin{array}{c}\text { Holes of } \\
\text { electric } \\
\text { socket }\end{array}$ & Height & 0.180 & 0.177 & 0.003 & 0.000009 \\
\cline { 2 - 6 } & Width & 0.343 & 0.343 & 0.000 & 0.000000 \\
\cline { 2 - 6 } & Length & 0.134 & 0.133 & 0.001 & 0.000001 \\
\hline \multirow{2}{*}{$\begin{array}{c}\text { Electric } \\
\text { box } \\
\text { (square) }\end{array}$} & Height & 0.083 & 0.1 & 0.000 & 0.000000 \\
\cline { 2 - 6 } & Width & 0.083 & 0.082 & 0.001 & 0.000001 \\
\cline { 2 - 6 } & Length & 0.040 & 0.039 & 0.001 & 0.000016 \\
\hline
\end{tabular}

Table 3 Comparison of measurement between conventional method (measure tape) and point clouds data by using TLS 


\begin{tabular}{|c|c|c|c|c|c|}
\hline Feature & $\begin{array}{l}\text { Dimen } \\
\text {-sions }\end{array}$ & $\begin{array}{c}\text { Measure } \\
\text { Tape } \\
\text { (m) }\end{array}$ & $\begin{array}{c}\text { Depth } \\
\text { Sensor } \\
\text { (m) }\end{array}$ & $\begin{array}{c}\text { Diff. } \\
(\mathbf{X})\end{array}$ & $\mathbf{X}^{2}$ \\
\hline \multirow{3}{*}{$\begin{array}{l}\text { Electric } \\
\text { box (L } \\
\text { shape) }\end{array}$} & Height & 0.100 & 0.098 & 0.002 & 0.000004 \\
\hline & Width & 0.150 & 0.147 & 0.003 & 0.000009 \\
\hline & Length & 0.178 & 0.171 & 0.007 & 0.000049 \\
\hline \multirow{3}{*}{$\begin{array}{l}\text { Holes of } \\
\text { electric } \\
\text { socket }\end{array}$} & Height & 0.180 & 0.176 & 0.004 & 0.000016 \\
\hline & Width & 0.343 & 0.330 & 0.013 & 0.000169 \\
\hline & Length & 0.134 & 0.135 & 0.001 & 0.000001 \\
\hline \multirow{3}{*}{$\begin{array}{l}\text { Electric } \\
\text { box } \\
\text { (square) }\end{array}$} & Height & 0.083 & 0.080 & 0.003 & 0.000009 \\
\hline & Width & 0.083 & 0.083 & 0.000 & 0.000000 \\
\hline & Length & 0.040 & 0.036 & 0.004 & 0.000016 \\
\hline & & & & Total & 0.000273 \\
\hline & & & & $\begin{array}{c}\text { Ave } \\
\text {-rage }\end{array}$ & 0.0000303 \\
\hline & & & & RMSE & 0.005 \\
\hline
\end{tabular}

Table 4 Comparison of measurement between conventional method (measure tape) and point cloud data by using depth sensor

Based on the result shown in table above, the RMSE value between conventional method (measure tape) and point clouds by TLS was $0.003 \mathrm{~m}$ and the RMSE value between conventional method (measure tape) and point clouds by TLS was $0.005 \mathrm{~m}$

It also showed that the measurement of depth of holes of electric socket is the highest measurements difference because the position of the object is shallow and complex to be detected by sensor. As mentioned before, based on specifications of depth sensor, the operating range of the sensor is between $0.5 \mathrm{~m}$ to $5.0 \mathrm{~m}$. The increasing distance of object to the sensor will lead to an increase in random error of depth measurement (Kourosh Khoshelham and Sander Oude Elberink, 2012). According to the comparison, it can be concluded that depth sensor is sufficient to produce $3 \mathrm{D}$ indoor model in accurate measurements but the accuracy is slightly lower than TLS data.

\subsection{Suitability in indoor application}

The 3D model for indoor spaces by using depth sensor is sufficient in low accuracy 3D model application. In facility management application, 3D model is useful for users to calculate area or volume of apartment or office which makes it easier to make a decision such as performing taxation and estimation quantities as well as cost needed to place a carpet in the office. The required information in the facility management is about vertical elements, internal structure of buildings, and even "invisible" information about pipe and cables integrated in walls and floors/ceilings (Sisi Zlatanova and Umit Isikdag, 2015). Besides that, changing it to GIS environment makes it easier to monitor, visualise, display, store and analyse for decision making.

The development of technology in positioning and localisation leads to high demand in 3D model positioning and navigation. Most of the indoor model application was required to integrate $3 \mathrm{D}$ indoor model with navigation or positioning. The 3D model for indoor spaces in this paper can be integrated with semantic information to help in indoor navigation processes, facilities management operations, indoor location based services, emergency response and other fields.
The availability of geometric and semantic information in 3D model for indoor spaces are also required by emergency responders to identify the number of crew and the designated 3D routes for each person (including which entrance/exit and ingress/egress path to use). This can reduce the planning time, total response time and critical on-scene investigation (Seyedeh, 2017).

\section{CONCLUSION}

This paper focused on the data acquisition and modelling of a 3D model for an indoor space by using a depth sensor. The EyesMap3D Pro depth sensor was able to generate 3D point clouds in high speed and high mobility due to the portability and light weight of the device. Besides, it can overcome the problem from existing equipment used in generating the 3D model in terms of time, cost and expertise. There are also some other elements affecting the depth sensor performance. For example, an object with reflective material (like a mirror) can lead to a problem that the IR (Infrared) light emitted by depth sensor cannot be reflected back to the camera, making the depth values unreliable or unable to be determined. Similarly, an object covered with light-absorbing materials (like carbon black) can cause less IR light reflected back to the camera. This can cause some of the point clouds missing and lead to less dense point cloud.

From the results, the evaluation of the 3D model for indoor spaces with specification and requirement of indoor applications showed that the data are sufficient to use in particular indoor applications and applicable in several applications that do not demand high accuracy. The data obtained represents the surfaces of the room but, this data does not fulfil the requirement of indoor model for navigation. The final result of 3D indoor model was exported to 3D GIS-ready format for displaying and storing more attribute information of the indoor spaces. 3D model in GIS environment can provide more understanding and analysis in decision making.

The finished model is good for visualisation purposes and could be used for some measuring functions only. There are numerous researches done on indoor navigation in $3 \mathrm{D}$ modelling. The development of indoor navigation techniques is reliant upon a constant, rich 3D information model for building interiors, considered within the wide context of indoor modelling. The geographic information system offers the function of displaying, analysing, update and edit information that can help in decision making. The 3D model exported in GIS ready information can be used in developing a database for indoor spaces inventory. An integration with semantic information is recommended to ensure the data have rich information that can help in decision making process. A flexible system with a wider range of application can be obtained through connecting spatial database with $3 \mathrm{D}$ models.

\section{ACKNOWLEDGEMENT}

This research was partially funded by UTM Research University Grant, Vot Q.J130000.3552.05G34 and Vot Q.J130000.3552.06G41. This research is also part of the collaboration between 3D GIS Research Lab, UTM and eCapture3D (Ecapture Research and Development SL). eCapture has provided eyesMap3D for this research. 


\section{REFERENCES}

Azri, S., Ujang, U., Abdul Rahman, A., 2019. 3D Geoclustering for Wireless Sensor Network in Smart City. Int. Arch. Photogramm. Remote Sens. Spatial Inf. Sci. XLII4/W12, 11-16.

Azri, S., Ujang, U., Castro, F.A., Abdul Rahman, A., Mioc, D., 2016. Classified and clustered data constellation: An efficient approach of 3D urban data management. ISPRS Journal of Photogrammetry and Remote Sensing 113, 30-42.

Azri, S., Ujang, U., François, A., Darka, M., Alias, A.R., 2014. Spatial Access Method for Urban Geospatial Database Management: An Efficient Approach of 3D Vector Data Clustering Technique, 9th International Conference on Digital Information Management (ICDIM). IEEE, Bangkok, Thailand.

Gunduz, M., Isikdag, U., \& Basaraner, M. 2016. A review of recent research in indoor modelling \& mapping. International Archives of the Photogrammetry, Remote Sensing and Spatial Information Sciences

Izham, M.Y., Uznir, U., Alias, A.R., Ayob, K., Wan Ruslan, I., 2011. Influence of georeference for saturated excess overland flow modelling using 3D volumetric soft geoobjects. Computers \& Geosciences 37, 598-609.

Kaijaluoto, R., Hyyppä, A., 2015. Precise Indoor Localization for Mobile Laser Scanner. ISPRS - Int. Arch. Photogramm. Remote Sens. Spat. Inf. Sci.

Keling, N., Mohamad Yusoff, I., Lateh, H., Ujang, U., 2017. Highly Efficient Computer Oriented Octree Data Structure and Neighbours Search in 3D GIS, in: Abdul-Rahman, A. (Ed.), Advances in 3D Geoinformation. Springer International Publishing, Cham, pp. 285-303.

Y. Bergeon, I. Hadda, V. Křivánek, J. Motsch and A. Štefek. 2015. Low cost 3D mapping for indoor navigation, International Conference on Military Technologies (ICMT) 2015, Brno, 2015, pp. 1-5.doi

M. Kim, B. Li, J. Park, S. Lee and H. Sohn. 2014. Optimal locations of terrestrial laser scanner for indoor mapping using genetic algorithm, The 2014 International Conference on Control, Automation and Information Sciences (ICCAIS 2014), Gwangju.

Mohd, Z.H., Ujang, U., Choon, T.L., 2017. Heritage House Maintenance using 3D City Model Application Domain Extension Approach. International Archives of the Photogrammetry, Remote Sensing \& Spatial Information Sciences.

Chen, C., Yang, B. S., \& Song, S. 2016. Low cost and efficient 3D indoor mapping using multiple consumer RGB-D cameras. International Archives of the Photogrammetry, Remote Sensing and Spatial Information Sciences - ISPRS Archives, 2016 January(July), 169-174.

M.R. Andersen, T. Jensen, P. Lisouski, A.K. Mortensen M.K. Hansen, T. Gregersen and P. Ahrendt. (2012). Kinect Depth Sensor. Evaluation for Computer. Vision Aplications. Aarhus University
Böhler and Marbs, 2002. 3D scanning instruments. International Workshop on Scanning for Cultural Heritage Recording, Corfu, Greece.

Bornaz, Leandro \& Rinaudo, Fulvio. 2004. Terrestrial laser scanner data processing.

Wong Yen Nee. 2011. Application of terrestrial Laser Scanning for 3D Modelling Building. Bachelor Degree Project Report, Universiti Teknologi Malaysia, Skudai.

Martin, R. 2008. The Benefits of AutoCAD Map 3D to AutoCAD Users.

Dongzhen, J., Khoon, T. Y., Zneng, Z., \& Qi, Z. 2009. Indoor 3D Modeling and Visualization with a 3D Terrestrial Laser Scanner. 3D Geo-Information Sciences, 247-255.

P. Henry, M. Krainin, E. Herbst, X. Ren, and D. Fox. 2014. RGB-D mapping: Using depth cameras for dense 3D modeling of indoor environments. In Experimental Robotics,. Springer Berlin Heidelberg, pp. 477-491.

Xiao, Y., Zhan, Q., \& Pang, Q. 2007. 3D Data Acquisition by Terrestrial Laser Scanning for Protection of Historical Buildings. International Conference Wireless Communications, Networking and Mobile Computing, (pp. 5971-5974).

Díaz Vilariño, Lucia \& Khoshelham, Kourosh \& MartínezSánchez, Joaquin \& Arias, Pedro. 2015. 3D Modeling of Building Indoor Spaces and Closed Doors from Imagery and Point Clouds. Sensors (Basel, Switzerland). 15. 3491-512. 10.3390/s150203491.

E-Capture.2016. EyesMap3D Pro: user manual, Spain, Mérida, Badajoz

A. A. Rahman, S. Zlatanova, and M. Pilouk. 2000. The 3D GIS software development: global efforts from researchers and vendors, Geoinformation Science Journal, vol. 1, no. 2

G. Brown, C. Nagel, Dr. S. Zlatanova and Prof. T. Kolbe. 2012 Modelling 3D Topographic Space Against Indoor Navigation Requirements, Technische Universität Berlin, Raum H 5121, Straße des 17. Juni 135, 10623 Berlin -

Hae-Kyong Kang 1 and Ki-Joune Li 2. 2017. A Standard Indoor Spatial Data Model-OGC IndoorGML and Implementation Approaches.

Kourosh Khoshelham and Sander Oude Elberink. 2012. Accuracy and Resolution of Kinect Depth Data for Indoor Mapping Applications. Faculty of Geo-Information Science and Earth Observation, University of Twente

Sisi Zlatanova and Umit Isikdag. 2015. 3D Indoor Models and Their Applications. Faculty of Architecture and the Built Environment, Delft University of Technology, Delft, The Netherlands.

Seyedeh Hosna Tashakkori Hashemi. 2017. Indoor Search and Rescue Using a 3D Indoor Emergency Spatial Model

Ujang, U., Azri, S., Zahir, M., Abdul Rahman, A., Choon, T.L., 2018. Urban Heat Island Micro-Mapping via 3D City Model. Int. Arch. Photogramm. Remote Sens. Spatial Inf. Sci. XLII4/W10, 201-207. 
Y. Lee, S \& Majid, Zulkepli \& Setan, Halim. (2013). 3D data acquisition for indoor assets using terrestrial laser scanning. ISPRS Annals of Photogrammetry, Remote Sensing and Spatial Information Sciences. II-2/W1. 221-226. 10.5194/isprsannals-II-2-W1-221-2013.

Ozbay, Erdal \& Cinar, Ahmet. (2013). 3D Reconstruction Technique with Kinect and Point Cloud Computing.

Yun, Seokmin \& Choi, Jaewon \& Sun Won, Chee. (2019). Omnidirectional 3D Point Clouds Using Dual Kinect Sensors. Journal of Sensors. 2019. 1-17. 10.1155/2019/6295956.

Marian Petre \& Ed de Quincey. (2006). A gentle overview of software visualisation. PPIG Newsletter

Nuzzo, Luigia \& Leucci, Giovanni \& Negri, S \& T. Carrozzo, M \& Quarta, T. (2002). Application of 3D visualization techniques in the analysis of GPR data for archaeology. Annals of Geophysics. 45. 10.4401/ag-3517.

Ware, C., Hui, D., And Franck, G. 1993. Visualizing Object Oriented Software in Three Dimensions. in Proceedings of CASCON'93, Toronto, Ontario, Canada, October, pp. 612620.

Bertin, J., 2010. Semiology of Graphics: Diagrams, Networks, Maps. 1st edn, ESRI Press : Distributed by Ingram Publisher Services, Redlands, Calif

Jorge Chen, 2018. Defining Semantic Levels Of Detail For Indoor Maps. ISPRS Annals of the Photogrammetry, Remote Sensing and Spatial Information Sciences, Volume IV-4/W7, 2018 3rd International Conference on Smart Data and Smart Cities.

Tang, Lei \& Li, Lin \& Ying, Shen \& Lei, Yuan. (2018). A Full Level-of-Detail Specification for 3D Building Models Combining Indoor and Outdoor Scenes. ISPRS International Journal of Geo-Information. 7. 419. 10.3390/ijgi7110419.

Laakso, M.; Kiviniemi, A. The IFC Standard-A Review of History, Development, and Standardization. J. Inf. Technol. Constr.2012,17, 134-161

Li, K.J. Indoorgml-a Standard for Indoor Spatial Modeling. Int. Arch. Photogramm. Remote Sens. Spat. Inf.Sci. 2016, XLI-B4, 701-704

Yang, Bisheng \& Li, Qingquan \& Li, D. (2000). Building model creating and storing in $3 \mathrm{~d}$ urban gis.

Zhao, P., Hu, Q., Wang, S., Ai, M., \& Mao, Q. 2018. Panoramic image and three-axis laser scanner integrated approach for indoor 3D mapping. Remote Sensing, 10(8). 